\title{
Cytomegalovirus and disseminated histoplasmosis-related hemophagocytic lymphohistiocytosis syndrome in an HIV-patient late presenter with IRIS: a case report
}

\author{
Luz A. González-Hernández ${ }^{1,2}$, Monserrat Alvarez-Zavala², Rodolfo I. Cabrera-Silva², Pedro Martínez-Ayala', \\ Fernando Amador-Lara' ', Aída S. Ramírez-González' ${ }^{1}$ Ana L. Ron-Magaña ${ }^{3}$, Vida V. Ruiz Herrera', \\ Karina Sánchez-Reyes ${ }^{2^{*}}$ and Jaime F. Andrade-Villanueva ${ }^{1,2^{*}}$
}

\begin{abstract}
Background: Hemophagocytic lymphohistiocytosis syndrome $(H L S)$ is an immune-mediated life-threatening disease considered as a medical emergency, with a potentially fatal multisystem inflammatory outcome. We present a patient that developed HLS and was able to be diagnosed efficiently with the help of an academic research institute of immunology.

Case presentation: A 21 years old male Mexican with human immunodeficiency virus (HIV), late presenter; who developed cytomegalovirus (CMV) infection and a disseminated histoplasmosis-related HLS, as part of an immune reconstitution inflammatory syndrome (IRIS). The patient required a long course of corticotherapy, intravenous immunoglobulin and massive transfusions (more than 10 units in $24 \mathrm{~h}$, and a total of 83 units), besides amphotericin-B and ganciclovir treatment. An academic research institute of immunology aided in the accurate diagnosis of HLS with the implementation of tests not available within the hospital, thus improving the care provided to the patient. The patient recovered, was discharged, and continue to improve.
\end{abstract}

Conclusion: The objective of this report is to highlight the importance of having multidisciplinary support, including basic medical sciences groups providing specific tests that are sometimes very difficult to get, which provides a benefit to patients in the well-aimed diagnosis as part of applied translational medicine.

Keywords: Hemophagocytic lymphohistiocytosis syndrome, Cytomegalovirus, Disseminated histoplasmosis, HIV, Applied translational medicine, IRIS, Case report

\section{Background}

HLS is an immune-mediated life-threatening disease considered as a medical emergency, with a potentially fatal multisystem inflammatory outcome, mainly if the correct treatment is not applied early $[1,2]$. Antiretroviral

*Correspondence: karina_reyesqfb@hotmail.com; drjandradev@gmail.com

${ }^{2}$ HIV and Immunodeficiencies Research Institute, CUCS-University of Guadalajara, Guadalajara, Jalisco, Mexico

Full list of author information is available at the end of the article treatment (ART) initiation is sometimes associated with a generalized inflammatory response termed IRIS, which occurs in two forms: (1) "unmasking" IRIS refers to the flare-up of an underlying, previously undiagnosed infection soon after ART is started and (2) "paradoxical" IRIS refers to the worsening of a previously treated disease after ART initiation [3, 4]. We report here a young Mexican man with HIV-infection and an unmasking IRIS; who came to receive medical attention for oral ulcers, fever, diarrhea, myalgias, dyspnea, and pancytopenia. His 
thrombocytopenia worsened, and he developed profuse hemorrhage (up to $1.5 \mathrm{~L} /$ day), requiring massive blood transfusions, intravenous immunoglobulin, and corticotherapy. The HLS diagnosis was made with the support of an academic research institute of immunology focused on HIV and Immunodeficiencies (HIV and Immunodeficiencies Research Institute; InIVIH). The overall goal of InIVIH is to investigate the main molecular and immunological mechanisms involved in the pathogenesis of HIV and its complications in Mexican patients. With the expertise of the researchers doing specialized techniques, an accurate diagnosis was achieved and allowed for prompt treatment for the patient. This collaboration highlights the importance of having an applied translational medicine, especially in places where up to $79 \%$ of the HIV-infected patients are late presenters (patients starting antiretroviral therapy for HIV infection with $\mathrm{CD}^{+}{ }^{+} \mathrm{T}$ cells less than 200 cells $/ \mu \mathrm{L}$ ), and specialized techniques are unavailable or unaffordable [5].

\section{Case Presentation}

A 21-year-old male Mexican with HIV infection with a basal HIV viral load of 70,800 copies/mL, CD4 ${ }^{+} \mathrm{T}$ cells of 6 cells $/ \mu \mathrm{L}(3 \%)$ and $\mathrm{CD} 8^{+} \mathrm{T}$ cells of 88 cells $/ \mu \mathrm{L}$ (46\%), who started ART (abacavir/lamivudine/dolutegravir) one-month prior symptoms, came to us with 12 days of clinical evolution and complaining about a lower lip ulceration, fever, chills, diarrhea (Bristol Stool Scale: type 5), myalgias, progressive dyspnea, and generalized weakness. The patient had an arterial pressure of $98 / 60 \mathrm{mmHg}$, fever $\left(38^{\circ} \mathrm{C}\right)$, cachexia, dehydration, tachycardia (140 beats/min) without murmurs, polypnea (35 breaths/min), and multiple tattoos. Right eye with phthisis bulbi (due to previous ocular trauma), with painful and erythematosus lower lip ulcerations and painful cervical adenopathies $(0.5-2.5 \mathrm{~cm}$ in diameter). Pulmonary examination reported a bilateral decrease of the vesicular murmur and oxygen saturation of $85 \%$ by pulse oximeter. The patient presented hepatosplenomegaly, diffuse abdominal pain, and genital warts; neuromuscular alterations were not detected.

In the emergency department, he was diagnosed with sepsis, acute kidney injury KDIGO III and pancytopenia: hemoglobin: $6.0 \mathrm{~g} / \mathrm{dL}(12.2-18.1 \mathrm{~g} / \mathrm{dL})$, white blood cell count: $2.15 \times 10^{3} / \mu \mathrm{L}\left(4.6-10.2 \times 10^{3} / \mu \mathrm{L}\right)$, and platelet count: $21.53 \times 10^{3} / \mu \mathrm{L}\left(142-424 \times 10^{3} / \mu \mathrm{L}\right)$. Moreover, the patient had lactate: $4.3 \mathrm{mmol} / \mathrm{L}$, procalcitonin: $0.43 \mathrm{ng} / \mathrm{mL}$, triglycerides: $284 \mathrm{mg} / \mathrm{dL}(3.20 \mathrm{mmol} / \mathrm{L})$, D-Dimer $4557 \mathrm{ng} / \mathrm{mL}$, C-reactive protein: $56.9 \mathrm{mg} / \mathrm{L}$, creatinine: $1.38 \mathrm{mg} / \mathrm{dL}(0.5-1.2 \mathrm{mg} / \mathrm{dL})$, urea: $92.9 \mathrm{mg} / \mathrm{dL}$ (15-39 mg/dL), albumin: $1.3 \mathrm{~g} / \mathrm{dL}$, aspartate aminotransferase (AST): $173 \mathrm{IU} / \mathrm{L}$, lactate dehydrogenase (LDH): $1059 \mathrm{IU} / \mathrm{L}$, fibrinogen: $233 \mathrm{mg} / \mathrm{dL}$ (2.3 g/L), prothrombin time: 15.1/s, and Hepatitis C virus-positive (ChildTurcotte-Pugh Class B [Score 7]) and APRI Index 0.016 (Table 1). Urinalysis without pathological findings.

A chest X-ray showed fine bilateral reticular interstitial infiltrates (Fig. 1), and a computed tomography scan showed bilateral basal consolidation areas, interstitial and reticulonodular infiltrates (Fig. 2), suggestive of Pneumocystis jiroveci pneumonia (PCP).

Secondary to the fever, pancytopenia, and $>1000 \mathrm{IU} / \mathrm{L}$ $\mathrm{LDH}$ at day one, $3 \mathrm{mg} / \mathrm{kg} /$ day of liposomal amphotericin $\mathrm{B}$ was given empirically to treat probable Histoplasmosis and, due to suggestive radiological findings, empirical $160 \mathrm{mg} / 800 \mathrm{mg}$ trimethoprim/sulfamethoxazole (TMP/ SMX) was administered for PCP; as well as transfusions of fresh frozen plasma, platelets, and red blood cells. The fever improved; however, the hemorrhage and pancytopenia worsened, the lowest platelet count detected on the 4th day of hospital stay (Table 1). Therefore, we performed a bone marrow aspiration (BMA), where lymphoma and malignancy were discarded. Through a Wright-Giemsa staining, we observed Histoplasma capsulatum, an increased number of macrophages with active hemophagocytosis (Fig. 3, 4), and with a probable diagnosis of disseminated intravascular coagulation (DIC; a score of 6 according to the consensus guideline by hematologists as part of the International Society of Thrombosis and Hemostasis [ISTH] [6]). With the support of InIVIH, we evaluated the natural killer (NK) cells cytotoxic activity. By assessing membrane expression of CD107a in NK cells using flow cytometry after cytotoxic assays, we confirmed a significant reduction of the NK cells cytotoxicity. Sadly, due to the lack of reagents, the measurement of soluble $\alpha$-chain interleukin 2 receptor (sCD25) could not be performed.

The diagnosis of HLS was made based on (I) fever, (II) hepatosplenomegaly, (III) pancytopenia, (IV) hemophagocytosis in bone marrow aspirate smear, (V) hypertriglyceridemia, (VI) hypofibrinogenemia, (VII) hyperferritinemia ( $>500 \mathrm{ng} / \mathrm{mL}$ ) and (VIII) defective NK cells degranulation and cytotoxicity (H-score of:276, with $99.8 \%$ chance for HLS); thus, we started a daily dose of prednisone $40 \mathrm{mg}$. The patient had an inadequate response, and after 25-days of corticotherapy, he presented severe epistaxis refractory to platelets transfusion (51 units), romiplostim, and ethamsylate, which required nasal tamponade. He also developed a profuse hematochezia (up to $1.5 \mathrm{~L} /$ day), that required massive transfusions (more than ten units of packed red blood cells in $24 \mathrm{~h}$ and nine units of fresh frozen plasma) and tranexamic acid. This clinical evolution supported the empirical initiation of ganciclovir therapy, in addition to 3 days of intravenous immunoglobulin, while waiting for the CMV viral load results. The pancytopenia 
Table 1 Relevant laboratory tests from baseline to discharge

\begin{tabular}{|c|c|c|c|c|c|c|}
\hline Test (units) (reference values) & Day 0 & Day 6 & Day 15 & Day 23 & Day 29 & Day 62 \\
\hline Hemoglobin (g/dL) (12.2-18.1) & $6.0^{d}$ & 8.04 & 6.3 & 7.9 & 12.2 & 11.01 \\
\hline Platelets $\left(\times 10^{3} / \mu \mathrm{L}\right)(142-424)$ & $21.53^{d}$ & 6.99 & 39.75 & 30.98 & 350.10 & 112.40 \\
\hline White blood cells $\left(\times 10^{3} / \mu \mathrm{L}\right)(4.6-10.2)$ & $2.15^{\mathrm{d}}$ & 2.13 & 10.68 & 3.00 & 4.54 & 2.09 \\
\hline Neutrophils $\left(\times 10^{3} / \mu \mathrm{L}\right)(37-80 \%)$ & 1.72 & 1.97 & 10.03 & 2.75 & 4.29 & 1.58 \\
\hline Creatinine $(\mathrm{mg} / \mathrm{dL})(0.5-1.2)$ & 1.38 & 1.4 & 0.92 & 0.36 & 0.87 & 0.41 \\
\hline Urea (mg/dL) (15-39) & 92.9 & 90 & 103.9 & 44 & 25.8 & 26 \\
\hline Glucose (mg/dL) (60-125) & $125^{\mathrm{a}}$ & $159^{b}$ & $116^{b}$ & $130^{b}$ & 101 & 86 \\
\hline Sodium (mEq/L) (135-145) & 126 & 128 & 128 & 134 & 138 & 137 \\
\hline Potassium (mEq/L) (3.5-5.1) & 5.6 & 5.4 & 5.0 & 3.73 & 3.6 & 3.47 \\
\hline $\operatorname{ALT}(I U / L)(10-40)$ & 20 & 33 & 25 & 19 & 13 & 9 \\
\hline AST (IU/L) (10-50) & 173 & 83 & 32 & 18 & 18 & 9 \\
\hline CK (U/L) (38-174) & 40 & - & - & - & - & - \\
\hline Albumin $(\mathrm{g} / \mathrm{dL})(3.5-5.0)$ & 1.3 & 1.97 & 2.03 & 2.00 & 2.14 & 3.82 \\
\hline Total Bilirubin (mg/dL) (0-1) & 1 & 0.5 & 0.2 & 0.25 & 0.6 & 0.31 \\
\hline LDH (IU/L) (91-190) & 1059 & 208 & 127 & 100 & 116 & 100 \\
\hline PT (s) (9.5-13) & 15.1 & 14.3 & 16 & 14 & 15.4 & 11.5 \\
\hline PTT (s) (25.5-35.5) & 43.2 & 42.2 & 39.2 & 49 & 39.1 & 34.7 \\
\hline INR [1] & 1.36 & 1.29 & 1.54 & 1.35 & 1.39 & 1.10 \\
\hline Triglycerides (mg/dL) (35-160) & $284^{d}$ & - & - & - & - & 84 \\
\hline Fibrinogen (mg/dL) (200-480) & $233^{d}$ & 553 & 683 & 864 & 633 & 613 \\
\hline Ferritin $^{\mathrm{C}}(\mathrm{ng} / \mathrm{mL})(20-250)$ & $>5000^{d}$ & - & 4061.7 & - & - & - \\
\hline D-Dimer (ng/mL) $(<500)$ & 4557 & - & - & 1929 & - & - \\
\hline $\operatorname{CRP}(\mathrm{mg} / \mathrm{L})(<10)$ & 56.9 & - & - & 12.7 & - & - \\
\hline
\end{tabular}

PT, Prothrombin time; TPT, partial thromboplastin time; INR, international normalized ratio; ALT, alanine aminotransferase; AST, aspartate aminotransferase; LDH, lactate dehydrogenase; CRP, C-reactive protein; CK, creatine kinase

a Non-fasting glucose; ${ }^{b}$ patient under corticotherapy; ${ }^{\mathrm{C}}$ The ferritin lab test provided in our hospital has an upper max limit of $5000 \mathrm{ng} / \mathrm{mL} ;{ }^{\mathrm{d}}$ Parameter that fulfilled HLS diagnostic criteria

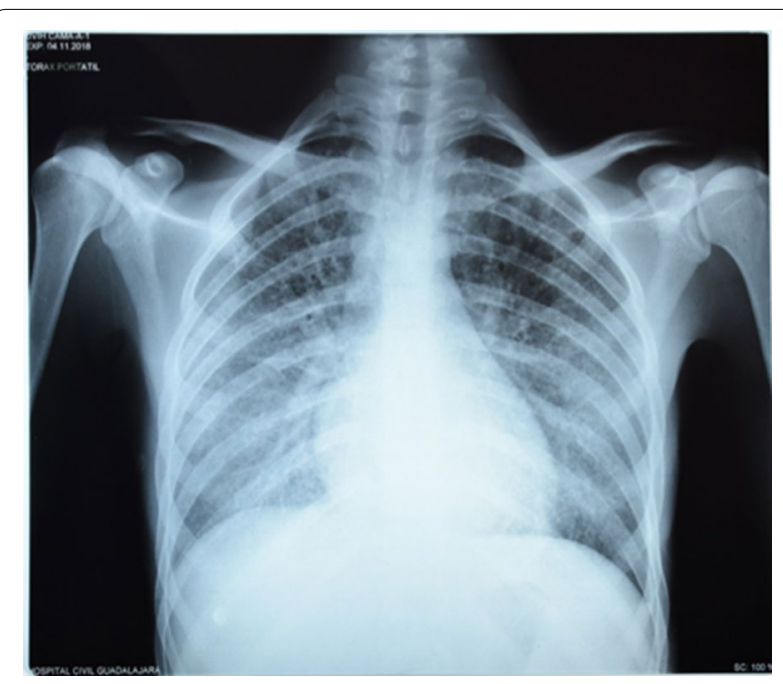

Fig. 1 Chest X-ray shows fine bilateral reticulo-interstitial infiltrates progressively improved, and the CMV qPCR test reported 237,616 IU/mL, confirming CMV infection.

The patient completed his treatment for disseminated histoplasmosis with amphotericin B for 14 days, followed by itraconazole as maintenance management. He was discharged 62 days after admission, with undetectable HIV viral load ( $<40$ copies/mL), CD $4^{+} \mathrm{T}$ cells of 10 cells/ $\mu \mathrm{L}(10 \%)$, and normalized standard laboratory studies. He remained stable in the subsequent clinical follow-up (Table 1). A summary of the patient's clinical evolution is shown in Fig. 5.

\section{Discussion and conclusions}

Described in 1939 by Scott and Robb-Smith, HLS is an immune-mediated life-threatening disease, which is characterized by uncontrolled hyperactivation of macrophages, histiocytes, and an impaired NK cells and cytotoxic $\mathrm{T}$ cell function, with a potentially fatal multisystem inflammatory outcome [1, 2]. HLS could be primary (or genetic, mainly reported in children, and discarded in this case) and secondary (or reactive). HLS is associated with many medical conditions, such as viral, bacterial, 


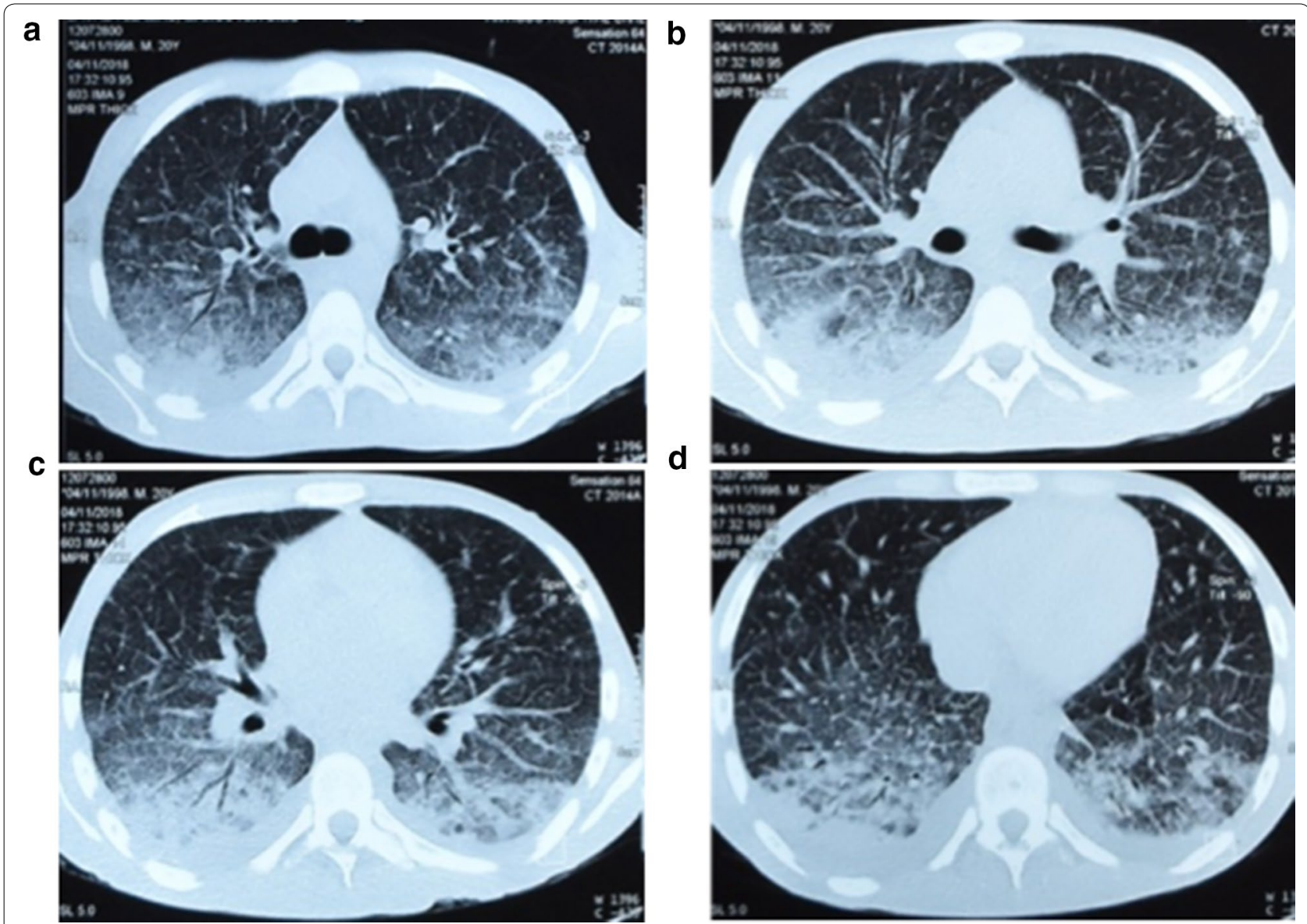

Fig. 2 a-d A chest computed tomography shows bilateral basal consolidation areas, interstitial and reticulonodular infiltrates at different levels

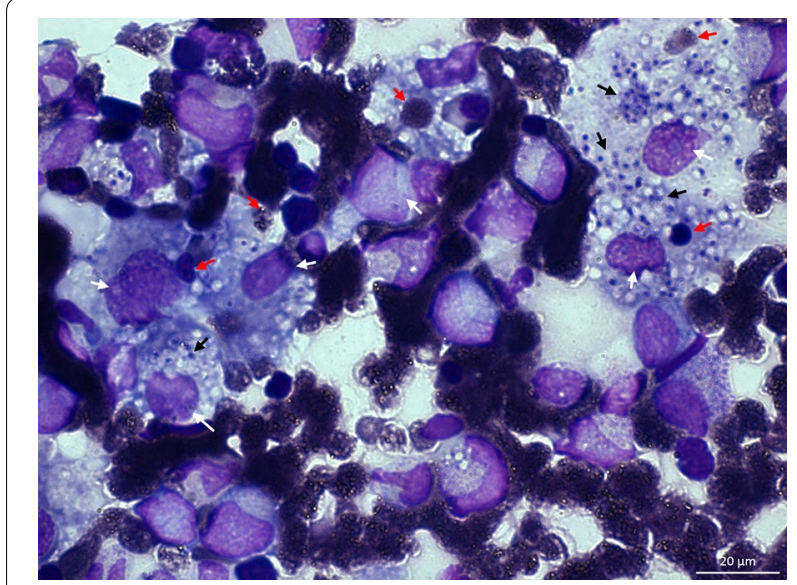

Fig. 3 Bone marrow aspirate shows reticulohistiocytic hyperplasia (white arrows) with phagocytized erythrocytes (red arrows), platelets, and abundant Histoplasma capsulatum yeast cells inside the

cytoplasm (black arrows). X100 optical zoom with oil immersion

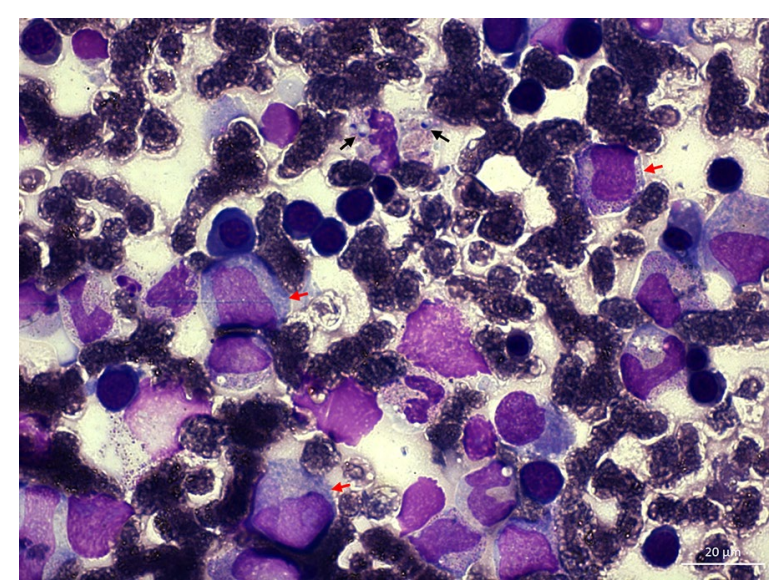

Fig. 4 Bone marrow aspirate shows monocytic hyperplasia (red arrows) with the presence of Histoplasma capsulatum spherules disperse through-out the aspirate (black arrows). X100 optical zoom with oil immersion 


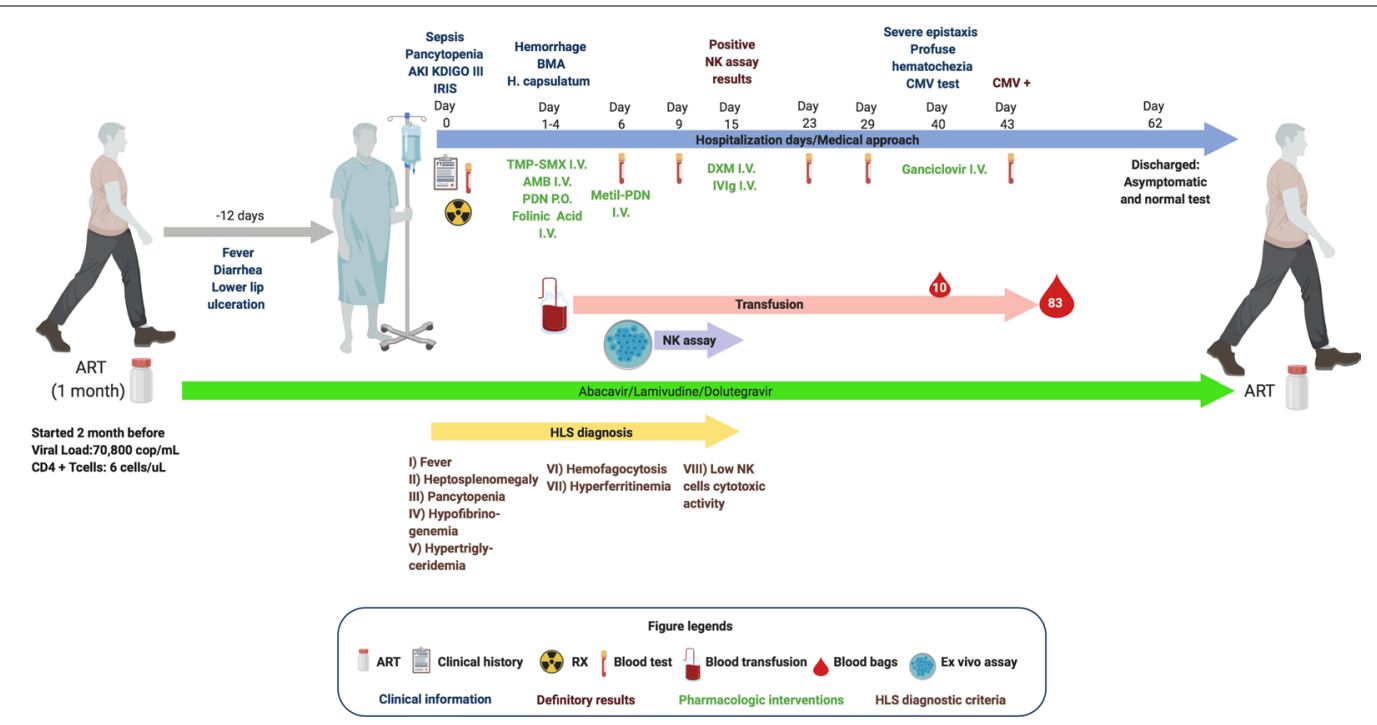

Fig. 5 After ART initiation, the patient began with fever, chills, lower lip ulceration, and diarrhea 12 days prior to hospitalization (gray arrow). On day 0 , the patient was diagnosed with sepsis, pancytopenia, AKI (KDIGO III), and IRIS; blood tests, Chest X-ray, and CT scan studies were performed. On day 1, empirical treatment for severe PCP and disseminated histoplasmosis was initiated; also, the patient started with hemorrhage, and blood transfusions (platelets, plasmapheresis, and red blood cells) were administered, which continued intermittently until day 43 (red arrow). On day 2 , hemophagocytosis and $H$. capsulatum were reported in a BMA. On day 9, support was requested to InIVIH, and samples were collected for NK cells cytotoxic assays. On day 13, low NK cells cytotoxic activity was confirmed (purple arrow), and a 3-day immunoglobulin treatment was provided. On day 40, severe epistaxis and hematochezia required massive transfusions (10 units in less than $24 \mathrm{~h}$; indicated by a blood droplet); empirical ganciclovir was provided while test results were reported. On day 43, CMV infection was confirmed. After 62 days and 83 blood transfusions, the patient was discharged with undetectable HIV viral load, $10 \mathrm{CD} 4^{+} \mathrm{T}$ cells count, and normal blood tests (blue arrow). During all this time, ART treatment was not suspended nor modified (green arrow). The yellow arrow indicates the process of HLS diagnosis. Created with BioRender. AKI: Acute Kidney Injury; AMB: Amphotericin B; ART: Antiretroviral Therapy; BMA: Bone Marrow Aspiration; CMV: Citomegalovirus; CT: Computed Tomography; DXM: Dexametasone; HLS: Hemophagocytic Lymphohistiocytosisi Syndrome; IRIS: Inmmune Reconsitution Inflammatory Syndrome; I.V: Intravenous; IVIg: intravenous gamma Immunoglobulin; Methyl-PDN: Methylprednisolone; PCP: Pneumocystis jiroveci Pneumonia; PDN: prednisone; P.O: oral administration; TMP-SMX: trimethoprim/sulfamethoxazole

parasitic, and fungal infections, neoplasms, autoimmune diseases, transplants, surgery, medications, vaccination, diabetes mellitus, chronic liver disease, pregnancy, and hemodialysis; sometimes, HLS remained idiopathic or with unknown etiology $[2,7]$.

In adults, the male-female ratio is $1: 7$, and the age at diagnosis is around 50 years. The principal factors that trigger HLS are external (drugs and infections) and, frequently, there is a basal underlying disease or disorder predisposing it (e.g., hematological cancer, systemic lupus erythematosus, or HIV infection) $[2,8]$.

Within HLS's pathophysiology, a low or absent NK cell activity occurs by a defect in granule-mediated cytotoxicity. Secondary to the absence of perforin and FAS systems (part of the inflammation control), there are an enhanced antigen presentation and uncontrolled activation of macrophages, histiocytes, and T cells. These cells create a cytokine storm, which develops a hemophagocytic lymphohistiocytosis, contributing to tissue injury, progressive systemic organ failure, and death [9].

Also, the release of pro-inflammatory cytokines promotes the hemophagocytosis, a hallmark of HLS
[7]. Previous reports indicate that the presence of hemophagocytosis has a sensitivity of $80-83 \%$ and a specificity of $60 \%$ for HLS; nevertheless, hemophagocytosis can be absent in some cases [10].

Often, the differential diagnosis between HLS, DIC, and sepsis is a challenge and, sometimes, it may be even impossible to rule out the coexistence of these pathologies. In a febrile patient without a transfusion history, no defect in the iron metabolism, pronounced cytopenias, and the presence of splenomegaly and high hyperferritinemia ( $>2000 \mathrm{ng} / \mathrm{mL}$ ), should guide the clinician towards the search for HLS [11]. Since the beginning, this case fulfilled six of the 8 criteria of the HLS-2004 guidelines (Table 2). These findings encouraged us to look for a defect in NK cell's cytotoxic activity to complete the diagnosis criteria. Regarding DIC, it is important to mention that the patient maintained a score of 6 (probable overt DIC) throughout his hospitalization until day 23 when his score decreased to 3 (not overt DIC). The DIC score was developed as a consensus guideline by hematologists as part of the ISTH. It is designed to be applied to patients with a critical illness 


\section{Table 2 Diagnosis Guidelines for HLS}

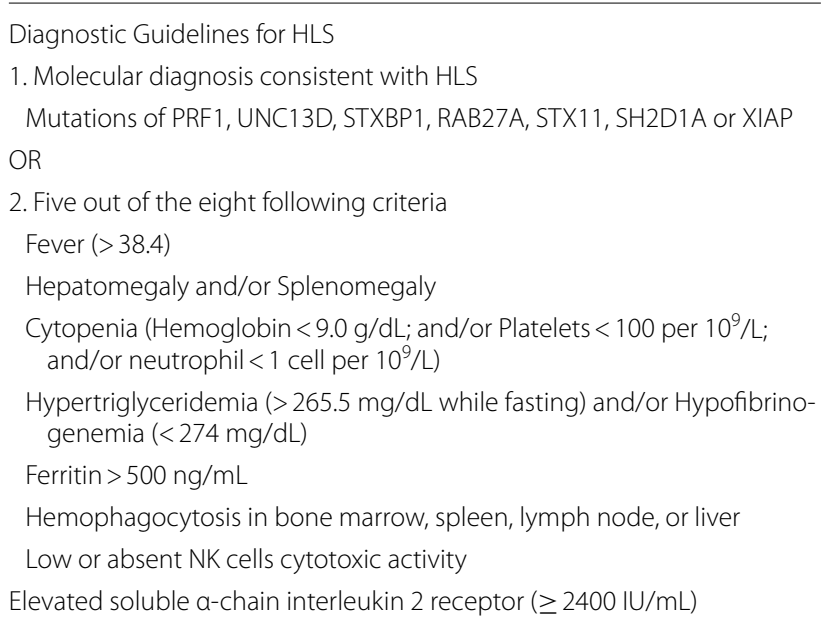

known that could precipitate DIC and categorizes patients into "probable overt DIC" and "not overt DIC" based on a series of laboratory parameters. This score is instrumental in tracing suspicion of DIC, and it is recommended to repeat the score every 1 or 2 days [6].

Following ART initiation, HIV+ patients can have an exaggerated inflammatory reaction to pathogenic microorganisms when the immune system begins to recover [12], a condition that could worsen the HLS. These events are known as IRIS (it can be paradoxical or unmasking), which have been reported most commonly in HIV late presenters with severe immunosuppression $\left(\leq 100\right.$ cells $/ \mu \mathrm{L}$ of $\mathrm{CD}^{+} \mathrm{T}$ cells) [4]. Since there is no diagnostic test for IRIS, confirmation of the syndrome relies heavily on clinical and laboratory data; however, there is not a standardized definition for diagnosis. Shelburne and et al. describe IRIS on HIV infection with effective ART (i.e., a decrease in HIV-1 RNA concentration or an increase $\mathrm{CD} 4^{+} \mathrm{T}$ cells count from baseline), and with clinical symptoms consistent with an inflammatory process. Besides, the clinical course should not be compatible with the expected course for previously diagnosed opportunistic infection, a newly diagnosed opportunistic infection, or drug toxicity [12, 13].

IRIS manifestations concord with the type of opportunistic infection, the latter depending on the epidemiology of each region. In Mexico, the leading causes reported are Mycobacterium tuberculosis infection, disseminated Mycobacterium avium complex, Pneumocystis jirovecii, Cryptococcosis, Histoplasmosis, CMV, and varicella-zoster virus. IRIS can be mild or life-threatening, as there is around two times more risk of death among patients with IRIS compared with patients without it $[4,14]$.
CMV infects the majority of adults, and during the primary infection, it can course with transient neutropenia and thrombocytopenia, followed by an asymptomatic viral latency period. CMV reactivation is more common in immunocompromised patients with depressed cell-mediated immunity, such as in HIVinfection. There are reports about pancytopenia secondary to CMV infection or reactivation $[15,16]$. Several mechanisms have been proposed to explain the deleterious effect of CMV on human hematopoietic function, including (1) Alteration of cell function by the production of inhibitory cytokines, (2) Perturbation of stromal cell functions with the subsequent reduced production of hematopoietic factors or disturbed expression of cell surface adhesion molecules, and (3) The direct infection of the hematopoietic stem or progenitor cells $[17,18]$. CMV infection in the bone marrow is a rare condition and is suspected when there are atypical cells in a BMA. A streptavidin-biotin-peroxidase detection system and diaminobenzidine staining can be used to identify a CMV bone marrow infection, as well as immunohistochemistry [19]. In this case report, there were no atypical cells in the BMA; therefore, immunohistochemistry was not performed. The pathogenesis of pancytopenia secondary to CMV infection is multifactorial; consequently, a broad diagnostic approach is required. Furthermore, AIDS patients sometimes require other drugs that could impact the bone marrow function, such as the case of TMP/SMX $[17,18]$, which in this case was given as treatment due to suspicion of PCP. However, cytopenia began prior to the administration of TMP/SMX, ruling out this possibility. Also, $15 \mathrm{mg}$ of folinic acid was administered daily since the pancytopenia was detected.

In patients with HIV infection, HLS could initiate by opportunistic or non-opportunistic diseases, neoplasms, the HIV itself, or even by ART initiation, especially in late presenters, mainly in patients who developed IRIS [20]. The literature suggests that the host genetic factors, rather than viral pathogenesis, determine the occurrence of HLS [21].

The clinical features of HLS are diverse and nonspecific; moreover, other inflammatory conditions can cause them. Thus, to assess the diagnosis of HLS, it is imperative to consider the updated criteria proposed by 'The Histiocyte Society' in 1991 (HLS 2004 guideline). The guidelines diagnose HLS by the molecular alterations consistent with HLS (for primary HLS), or by getting five out of eight criteria shown in Table 2 (for reactive HLS). The HLS 2004 guidelines have been found to have a similar specificity and sensibility to the $\mathrm{H}$-score. For the HLS 2004 guidelines, the sensitivity and specificity with at least 5 criteria is $80 \%$ and $95 \%$, respectively, while and 
$\mathrm{H}$-score with $>185$ points has $85 \%$ and $88 \%$, respectively [22].

Nonetheless, the HLS guidelines' criteria referred above are not available in many care centers, including our hospital, as many of the techniques required are not available, or they are unaffordable for the hospital or the patient. However, thanks to the support from InIVIH, we could evaluate the NK cells' cytotoxicity; we evaluated NK cells cytotoxic activity by flow cytometry. In isolated and stimulated NK cells, we measured the membrane expression of CD107a, a marker of immune cell activation, and cytotoxic degranulation for NK cells and CD8 ${ }^{+}$ $\mathrm{T}$ cells [23-25]. Through this assay, we detected the low expression of NK cells (0.6-5.1\%; normal expression goes around $10.3-17.4 \%$ ), thus fulfilling the criteria.

As mentioned previously, sCD25 levels were not measured due to the lack of adequate reagents. However, an indirect evaluation for sCD25 was attempted. By flow cytometry, concentrations of membrane CD25 on CD8 ${ }^{+}$ $\mathrm{T}$ cells were measured and found a $30 \%$ increase of CD25 levels when compared to a healthy person (age and sex paired). As the patient had low $\mathrm{CD} 4^{+} \mathrm{T}$ cell count, we hypothesized that the primary source of sCD25 is from the $\mathrm{CD}^{+} \mathrm{T}$ cell. As $\mathrm{CD} 8^{+} \mathrm{T}$ cells had an increased amount of membrane CD25, they could, eventually, cause high levels of sCD25; hence filling the last criteria for HLS.

Regardless, as this is not a confirmed technique for the measurement of $\mathrm{sCD} 25$, we did not add this measurement in the scoring and diagnosis of HLS in this patient.

Recently, the introduction of the H-Score redefined the cutoffs of the Histiocyte Society's HLS diagnosis; thus, adding the (I) underlying immunosuppression, (II) hepatosplenomegaly and (III) AST $>30$ IU/L to their criteria. Currently, the H-Score is mainly validated for reactive HLS. The probability of having HLS ranged from $<1 \%$ with an H-Score of 90 points or less to $>99 \%$ with an H-Score of 250 [26, 27]. The patient in this case report had a $276 \mathrm{H}$-Score.

Reactive HLS carries a high mortality, ranging from 52 to $74 \%$ at 1 year, depending of variables like patients older than 30 years, the presence of disseminated intravascular coagulation, elevated ferritin level, and anemia with accompanying thrombocytopenia [28]. HLS treatment consists of dexamethasone and etoposide [10]. In this paper, we described a patient with acquired immunodeficiency syndrome who presented HLS related to an unmasked IRIS, secondary to disseminated histoplasmosis and CMV infection. The patient required more than 80 transfusion units, romiplostim, tranexamic acid, a long course of corticotherapy (without etoposide), intravenous immunoglobulin, and a long list of supportive measures. Although the patient was in a critical condition, the early identification of HLS allowed the implementation of the right treatment. The aid provided by InIVIH hastened the diagnosis and led to prompt therapy. Also, it highlighted the importance of having an applied translational medicine with medical sciences research groups, especially in places where there are many HIV late presenters with the risk of developing pathologies with a difficult diagnosis.

HLS is a multifaceted, potentially life-threatening clinical syndrome without specific clinical findings; thus, HLS requires a high degree of suspicion and a multidisciplinary approach by clinicians (including immunologists, hematologists, and infectious disease specialists) for the early diagnosis and the correct treatment of the underlying etiology, plus an immunosuppressant therapy. For HLS, some diagnostic clues include high fever (unresponsive to broad-spectrum antibiotics), hypertriglyceridemia, hypofibrinogenemia, hyperferritinemia, cytopenia, visceromegaly, and a BMA smear with hemophagocytosis. Furthermore, having access to a research institute that provides support with a specialized immunological assay, not only makes it easier for clinicians to have greater certainty in the diagnosis of HLS but it can also accelerate it, mainly in places where these types of lab test are not available or affordable -like in our settings. Therefore, we want to emphasize the need for collaboration with research laboratories in the clinical field to offer more accurate diagnoses through these specialized tests, which are sometimes part of the diagnostic criteria, like in HLS. This case report shows that the collaboration between medical and basic sciences is essential for the progression of translational medicine and the improvement of medical care. It is clear that the early identification of the causative agents, made possible thanks to the support of a research group, as well as the initiation of the appropriate treatment, significantly contributed to this patient's survival.

\section{Abbreviations}

AIDS: Acquired Immunodeficiency Syndrome; ART: Antiretroviral Treatment; AST: Aspartate Aminotransferase; BMA: Bone Marrow Aspiration; CD25: Interleukin 2 Receptor; SCD25: Soluble Interleukin 2 Receptor; CMV: Cytomegalovirus; DIC: Disseminated Intravascular Coagulation; HIV: Human Immunodeficiency Virus; HLS: Hemophagocytic Lymphohistiocytosis Syndrome; IRIS: Immune Reconstitution Inflammatory Syndrome; ISTH: International Society of Thrombosis and Hemostasis; InIVIH: HIV and Immunodeficiencies Research Institute; LDH: Lactate Dehydrogenase; NK cells: Natural Killer cells; PCP: Pneumocystis jiroveci Pneumonia; TMP/SMX: Trimethoprim/Sulfamethoxazole.

\section{Acknowledgements}

We thank the hematology service for their clinical support, as well as the blood bank staff for helping with the transfusions this patient required. Furthermore, we want to thank Ph.D. Pablo Cesar Ortiz Lazareno for providing the antibody and guidance for the NK cytotoxic assay. Last but not least, we wish to thank the patient and healthy control for their consent. 


\begin{abstract}
Authors' contributions
JA, LG, PM, FA, VR, AR-G provided clinical care and performed the clinical evaluation, and laboratory tests assessment. AR-M helped with the bonemarrow assessment, diagnosis, and taking the images for this paper. MA, KS, RC performed cell culture and analysis of all tests related to NK cells and CD8 ${ }^{+}$ T cells function, as well as, CD107a and CD25 expression. RC, MA, KS, LG, JA did the literature search, manuscript writing, review and editing. MA, KS, LG, $\mathrm{RC}$ developed the tables and figures for this manuscript. All authors read and approved the final manuscript.
\end{abstract}

\section{Funding}

This work did not have funding.

\section{Availability of data and materials}

All data generated or analyzed during this study are included in this published article.

\section{Ethics approval and consent to participate}

The patient signed a written informed consent for clinical care. Our study has been granted an exemption from review by the ethics committee in research of the "Antiguo Hospital Civil de Guadalajara_Fray Antonio Alcalde."

\section{Consent for publication}

Written informed consent for publication of their clinical details and clinical images was obtained from the patient.

\section{Competing interests}

The authors declare that they have no competing interests.

\section{Author details}

1 HIV Unit, Antiguo Hospital Civil de Guadalajara "Fray Antonio Alcalde" Guadalajara, Jalisco, Mexico. ${ }^{2}$ HIV and Immunodeficiencies Research Institute, CUCS-University of Guadalajara, Guadalajara, Jalisco, Mexico. ${ }^{3}$ Hematology and Trasplant Unit, Hospital Civil de Guadalajara "Fray Antonio Alcalde", Guadalajara, Jalisco, Mexico.

Received: 28 January 2020 Accepted: 22 July 2020

Published online: 14 August 2020

\section{References}

1. Sen ES, Steward CG, Ramanan AV. Diagnosing haemophagocytic syndrome. Arch Dis Child. 2017;102(3):279-84. https://doi.org/10.1136/archd ischild-2016-310772.

2. Ramos-Casals M, Brito-Zerón P, López-Guillermo A, Khamashta MA, Bosch X. Adult haemophagocytic syndrome. Lancet. 2014;383(9927):1503-16.

3. AIDSinfo. Glossary of HIV/AIDS-Related Terms. 9th ed, Vol. 9. 2018. https:// aidsinfo.nih.gov/contentfiles/glossaryhivrelatedterms_english.pdf.

4. Hoyo-Ulloa I, Belaunzarán-Zamudio PF, Crabtree-Ramirez B, GalindoFraga A, Pérez-Aguinaga ME, Sierra-Madero JG. Impact of the immune reconstitution inflammatory syndrome (IRIS) on mortality and morbidity in HIV-infected patients in Mexico. Int J Infect Dis. 2011;15(6):e408-14.

5. Crabtree-Ramírez B, Caro-Vega Y, Shepherd BE, Wehbe F, Cesar C, Cortés C, et al. Cross-Sectional Analysis of Late HAART Initiation in Latin America and the Caribbean: late testers and late presenters. PLoS ONE. 2011;6(5):e20272. https://doi.org/10.1371/journal.pone.0020272.

6. Levi M, Toh $\mathrm{CH}$, Thachil J, Watson HG. Guidelines for the diagnosis and management of disseminated intravascular coagulation. Br J Haematol. 2009;145(1):24-33.

7. Fisman DN. Hemophagocytic syndromes and infection. Emerg Infect Dis. 2000;6(6):601-8.

8. Janka GE, Lehmberg K. Hemophagocytic syndromes-an update. Blood Rev. 2014;28(4):135-42. https://doi.org/10.1016/j.blre.2014.03.002.

9. Chen M, Felix K, Wang J. Critical role for perforin and Fas-dependent killing of dendritic cells in the control of inflammation. Blood. 2012;119(1):127-36. https://doi.org/10.1182/blood-2011-06-363994.

10. Aravamudan VM, Er C, Hussain I, Cheong N, Chern HC, Kuthah N, et al. A case of parvovirus-related haemophagocytic lymphohistiocytosis in a patient with HbH Disease. Case Rep Med. 2018;2018(2):1-4.
11. Machowicz R, Janka G, Wiktor-Jedrzejczak W. Similar but not the same: differential diagnosis of HLH and sepsis. Crit Rev Oncol Hematol. 2017:114:1-12.

12. Meintjes G, Lawn SD, Scano F, Maartens G, French MA, Worodria W, et al. Tuberculosis-associated immune reconstitution inflammatory syndrome: case definitions for use in resource-limited settings. Lancet Infect Dis. 2008:8(8):516-23.

13. Shelburne SA, Montes M, Hamill RJ. Immune reconstitution inflammatory syndrome: more answers, more questions. J Antimicrob Chemother. 2006;57(2):167-70. http://academic.oup.com/jac/article/57/2/167/80463 9/Immune-reconstitution-inflammatory-syndrome-more.

14. Novak RM, Richardson JT, Buchacz K, Chmiel JS, Durham MD, Palella FJ, et al. Immune reconstitution inflammatory syndrome. AIDS. 2012;26(6):721-30

15. Koukoulaki M, Ifanti G, Grispou E, Papastamopoulos V, Chroni G, Diamantopoulos E, et al. Fulminant pancytopenia due to cytomegalovirus infection in an immunocompetent adult. Brazilian J Infect Dis. 2010;14(2):180-2.

16. Tse JR, Ng GX. Pancytopenia secondary to cytomegalovirus reactivation. Case Reports. 2014. https://doi.org/10.1136/bcr-2013-201857.

17. Almeida-Porada GD, Ascenso JL. Cytomegalovirus as a cause of pancytopenia. Leuk Lymphoma. 1996;21(3-4):217-23.

18. Panel on Opportunistic Infections in Adults and Adolescents with HIV. Guidelines for the prevention and treatment of opportunistic infections in adults and adolescents with HIV: recommendations from the Centers for Disease Control and Prevention, the National Institutes of Health, and the HIV Medicine Association of the Inf. 2019.

19. Vassallo J, Huguet F, Brousset P. "In situ" detection of human cytomegalovirus infection of bone marrow in a patient previously treated for B-prolymphocytic leukaemia. J Clin Pathol. 2006;60(7):839-40.

20. Maakaroun NR, Moanna A, Jacob JT, Albrecht H. Viral infections associated with haemophagocytic syndrome. Rev Med Virol. 2010;20(2):93-105. https://doi.org/10.1093/ve/vew024.

21. Adachi E, Koibuchi T, Imai K, Kikuchi T, Shimizu S, Koga M, et al. Hemophagocytic syndrome in an acute human immunodeficiency virus infection. Intern Med. 2013;52(5):629-32.

22. Debaugnies F, Mahadeb B, Ferster A, Meuleman N, Rozen L, Demulder A, et al. Performances of the $\mathrm{H}$-Score for diagnosis of hemophagocytic lymphohistiocytosis in adult and pediatric patients. Am J Clin Pathol. 2016;145(6):862-70.

23. Alter G, Malenfant JM, Altfeld M. CD107a as a functional marker for the identification of natural killer cell activity. J Immunol Methods. 2004;294(1-2):15-22

24. Shabrish S, Gupta M, Madkaikar M. A modified NK cell degranulation assay applicable for routine evaluation of NK Cell Function. J Immunol Res. 2016;2016:1-6.

25. Nielsen C, Agergaard CN, Jakobsen MA, Møller MB, Fisker N, Barington T. Infantile hemophagocytic lymphohistiocytosis in a case of chediakhigashi syndrome caused by a mutation in the LYST/CHS1 Gene Presenting With Delayed Umbilical Cord Detachment and Diarrhea. J Pediatr Hematol Oncol. 2015;37(2):e73-9. http://www.embase.com/search/resul ts?subaction=viewrecord\&from $=$ export\&id $=$ L601149170\%0A. https:// doi.org/10.1097/mph.0000000000000300\%0ahttp://sfx.library.uu.nl/utrec ht? sid=embase\&issn=15363678\&id=

26. Fardet L, Galicier L, Lambotte O, Marzac C, Aumont C, Chahwan D, et al. Development and validation of the HScore, a score for the diagnosis of reactive hemophagocytic syndrome. Arthritis Rheumatol. 2014;66(9):2613-20. https://doi.org/10.1002/art.38690.

27. Tulloch $L G$, Younes $R$, Jeng A. Reactive hemophagocytic syndrome in the setting of acute human immunodeficiency virus 1 infection: case report and review of the literature. Int J STD AIDS. 2018;29(13):1354-8. https:// doi.org/10.1177/0956462418788689.

28. Sanchez A, Celaya AK, Victorio A. Histoplasmosis-associated hemophagocytic syndrome: a case report. AIDS Read. 2007;17(10):496.

\section{Publisher's Note}

Springer Nature remains neutral with regard to jurisdictional claims in published maps and institutional affiliations. 